\title{
APPLYING HARMONIC ANALYSIS \\ sciendo \\ IN THE MEASUREMENTS OF GEOMETRICAL \\ DEVIATIONS OF CRANKSHAFTS - ROUNDNESS SHAPES ANALYSIS
}

doi:10.2478/mape-2018-0024

Date of submission of the article to the Editor: 03/2018

Date of acceptance of the article by the Editor: 06/2018

MAPE 2018, volume 1, issue 1, pp. 185-189

Dr hab. inż. Krzysztof Nozdrzykowski, prof. AM

Maritime University of Szczecin, Poland

\begin{abstract}
The article presents measuring procedures and principles of determining deviations of shape and location of the crankshaft main necks assembly axis. We also described mathematical methods of roundness shapes description based on the harmonic analysis theory for the cases when the shaft is set with the external journals in prisms and for the case when the shaft is set on the external front faces in the claws. The results of sample calculations realized on the basis of the proposed mathematical methods have been presented in a form of diagrams of so called amplitude spectrum and in a graphic form of roundness shapes expressed in a polar coordinate system. The procedures described find a practical use during measurements of geometrical deviations of crankshafts realized on the basis of a measuring system with so called flexible support of the measured object.
\end{abstract}

Keywords: harmonic analysis, crankshafts, setting in claws or prisms, measuring procedures, principles of determining geometrical deviations

\section{INTRODUCTION}

Large size, monolithic crankshafts of marine engines are components of a complex geometry and high susceptibility to bending deformations (Sun et al., 2010; Quan et al., 2011; Walczyk et al., 2011). Due to their properties crankshafts require multi-point support. Maintaining deviations of shape and location of main bearings' components axes, which are support points for the crankshafts, ensures correct functioning of a crankshaft-and-piston system and, as a result, the whole marine engine. It concerns mainly the system of shaft main journals, which sprawl on long distances. The description of the geometrical form of the shaft main journals requires providing deviations and tolerances of roundness and cylindricity and their mutual location of the axis, namely concentricity and parallelism.

In accordance with the guidelines of Geometrical Product Specification one has to apply so called adjacent elements (lines, circles, and adjacent surfaces) when determining shape deviations. On the other hand, when defining direction, location and beating deviations it is necessary to apply so called elements of reference (these are points, lines or surfaces with reference to which one can define the location of other points, lines or surfaces). From the perspective of cylindrical surfaces system cooperation one of the significant location deviations is concentricity deviation which, according to the literature (Humienny, 2001; Jakubiec and Malinowski, 2004; Malinowski, 1998; Meaedows, 1995) can be defined with respect to another axis, system of bases or adopted mutual axis.

Practical realization of the base during concentricity measurements can be performed with the use of setting claws (it concerns small-size shafts) or via setting the shaft in the prisms.

Setting the object in the prisms is the most common way used when dealing with large cylindrical machine components due to the simplicity of construction and craftsmanship of prisms, possibility of bearing high loads, as well as the possibility of turning the object in the prisms during taking measurements, especially when using roller prisms. A correct 
assessment of the measured deviations of shape and axis location depends on the reference correctly defined during elaborating the results for reference elements' measurements and on the scrupulous analysis of the errors of a measuring method used. Strict defining of reference element (reference axis) when setting a crankshaft in the prisms is troublesome. It is so due to high susceptibility and changes in location of the measured object which are dependent on its size and way of support, as well as due to measuring system parameters and the parameters of cylindrical surfaces describing the shape of a given system (Azirjawi and Basheer, 2018; Dai et al., 2006).

\section{MEASURING PROCEDURES AND PRINCIPLES OF DEFINING PARAMETERS WHICH DESCRIBE A REAL SHAPE OF ROUNDNESS WHEN SETTING THE SHAFT IN THE EXTERNAL JOURNALS IN PRISMS OR SETTING CLAWS}

In general, measurements of the object set in prisms or claws are in fact measurements of the complex shape and axis location deviation, which are realized in the consecutive cross sections of the journals' system of a turning crankshaft. The middle of a measured cross section shape can change the position in case of setting the shaft in the prisms with respect to the axis of rotation realized by the measuring system or with respect to the axis realized by the claws in case the shaft is set in the claws. Measuring results include the description of the measured cross section shape contour and eccentricity which represents placing the middle of the cross section contour measured with respect to the axis of rotation realized by the measuring system or the claws. Such a measuring method requires developing the results in two stages, first of which enables defining shape deviations, and second - defining axis location deviations (Nozdrzykowski K., 2010). It has been assumed that a mean square element will be a reference element on both stages. Adopting a mean square element as a reference element for the assessment of shape and axis location deviations was dictated by a range of advantages of this element type, what has been pointed out in the literature (Adamczak, 1998; Żebrowska-Łucyk, 1979). In case of shape contour assessment it was a mean square circle obtained from the measured shape contour, but in case of concentricity assessment it was a mean square axis obtained from the defined before centres of particular shape contours measured in given cross sections on the shaft length. A harmonic analysis of the roundness contours allows presenting the contours measured in this way in form of sum of Fourier series trigonometrical expressions (for instance, in form of so called finite cosine transform) what, in case of the contour being defined with respect to the middle circle, corresponds to the mathematical formula:

$$
\Delta F(\varphi)=\sum_{n=1}^{k} C_{F n} \cos n\left(\varphi-\varphi_{F n}\right)
$$

where:

$C_{F n}$ - amplitude of the consecutive

$n$ - measured harmonic contour,

$\varphi_{F n}$ - phase shift of the consecutive

$n$ - harmonic.

or:

$$
\Delta F(\varphi)=\sum_{n=1}^{k} A_{F n} \cos n \varphi+\sum_{n=1}^{k} B_{F n} \sin n \varphi
$$

where:

$A_{F n}, B_{F n}$ - amplitudes' compounds of the consecutive

$n$ - harmonics of measured contour.

Amplitudes' compounds of the consecutive harmonics are described with the following relations commonly used for the numerical calculations (Adamczak, 1998; Nozdrzykowski, 2010): 


$$
\begin{aligned}
& A_{F n}=\frac{2}{n_{j}} \sum_{j=1}^{n_{j}} r_{j} \cos n \frac{2 \pi j}{n_{j}} \\
& B_{F n}=\frac{2}{n_{j}} \sum_{j=1}^{n_{j}} r_{j} \sin n \frac{2 \pi j}{n_{j}}
\end{aligned}
$$

where:

$r_{j}$ - digitized values of the function $\Delta F(\varphi)$,

$n_{j}$ - number of ranges adopted for digitalization,

$n$ - number of the following harmonic.

Amplitudes $C_{F n}$ of the particular harmonics and their phase shifts are expressed in the relations:

$$
\begin{gathered}
C_{F n}=\sqrt{A_{F n}^{2}+B_{F n}^{2}} \\
\operatorname{tg} n \varphi_{F n}=\frac{B_{F n}}{A_{F n}}
\end{gathered}
$$

Adopted measuring procedure is realized in the polar system. The consecutive values of the radius $r_{j i}$ change at the particular angle of shaft rotation $\varphi_{j i}$ are the measured values in particular cross sections $I_{i}$.

Taking into account that the revolution of the shaft will always have a constant angle value $\varphi_{j i}$, according to (Adamczak, 1998; Nozdrzykowski, 2010) the coordinates $x_{j}$ and $y_{j}$ of the centre of any roundness contour $i$ (located on the length $l_{i}$ ), referred to the axis of rotation realized by the measuring system one can be determined from the relation (3) and (4) assuming that $n=1$. As shown in (Nozdrzykowski, K., 2010), a measured roundness contour $\Delta F(\varphi)$, in case of referential measurements realized at the setting a measuring object with the external journals in the prisms can be expressed as a following function:

where:

$$
\Delta F(\varphi)=\Delta R_{e}(\omega, \varphi)+e(\omega, \varphi)+\Delta R_{1,2}\left(\alpha, \gamma, l_{1}, l, \varphi\right)
$$

$\Delta R_{e}(\omega, \varphi)$ - compound of the actual roundness contour dependant on the eccentricity $e$ and its angle position $\omega$;

$e(\omega, \varphi)$-compound of the eccentric actual centre shift of the roundness contour with respect to the axis of rotation realized by the prism system;

$\Delta R_{1,2}(\alpha, \gamma, l, l, \varphi)$ - compound of the actual roundness contour axis of rotation position change dependant on irregularity of roundness contours connected to the generating functions of setting prisms and measuring system parameters (angles $\alpha$ and $\gamma$ ).

Being familiar with the parameters describing the compounds $e(\omega, \varphi)$ and $\Delta R_{1,2}(\alpha, \gamma, l, I, \varphi)$, allows for defining an actual contour $\Delta R_{e}(\omega, \varphi)$ and actual roundness deviation $\Delta R$ from the measured roundness contour $\Delta F(\varphi)$.

Comparing the equations (1) and (7) and developing them as well as making further transitions it has been stated that for the case of setting the shaft with external journals in the prisms, on the basis of developed transfer function we can determine the compounds $A_{R n}, B_{R n}$ of amplitudes of the particular actual transferred contour harmonics $\Delta R_{p}(\varphi)$ at the known compound values of measured contour harmonics amplitudes $\Delta F(\varphi)$, compound of actual transformed contour harmonics amplitudes $\Delta R_{p 1}(\varphi), \Delta R_{p 2}(\varphi)$, resulting from already known measured roundness contours connected to generating functions of setting prisms $\Delta F_{1}(\varphi)$, $\Delta F_{2}(\varphi)$. A converted actual contour can be then expressed as a Fourier trigonometrical series:

$$
\Delta R_{p}(\varphi)=\sum_{n=2}^{k} C_{R n p} \cos \left(n \varphi-\operatorname{arctg} \frac{B_{R n}}{A_{R n}}\right)
$$


An actual converted contour $\Delta R_{p}(\varphi)$ achieved as a result of transformation is compliant with an actual contour $\Delta R_{e}(\varphi)$ within the margin of error in the assumed baseline data and transformation method used. A measured contour $\Delta F(\varphi)$ substantially differs from the actual contour, what has been presented in a graphic form in Fig. 1.

a)

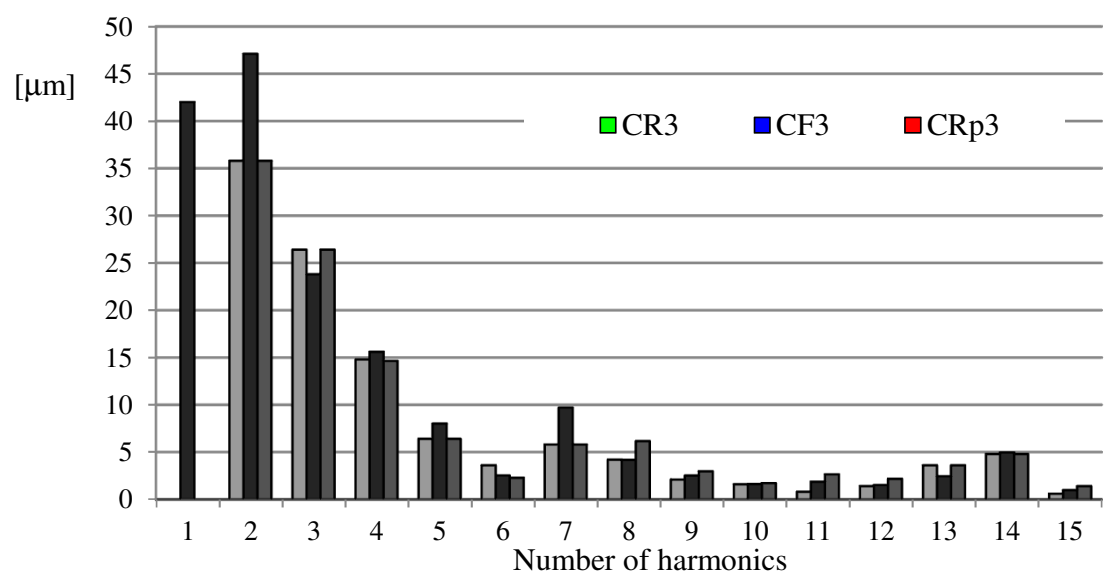

b)

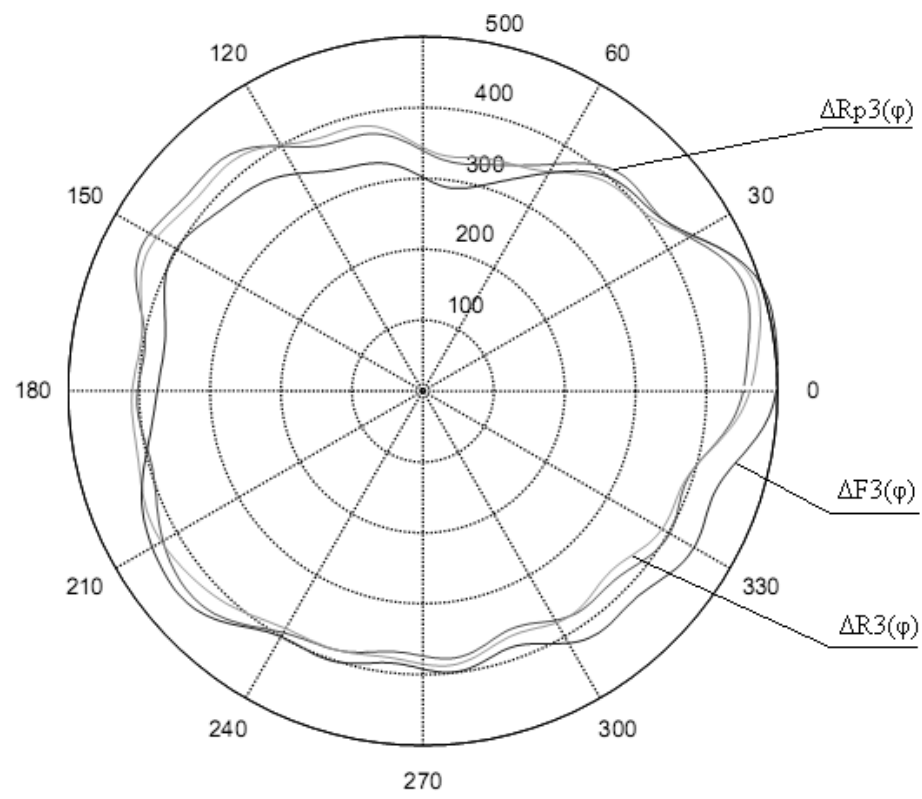

Fig. 1. Roundness contour in a form of: a) amplitude spectrum: b) diagram in a polar coordinates system, where: $\Delta F(\varphi)$ - measured roundness contour, $\Delta R_{p}(\varphi)$ - actual converted contour, $\Delta R(\varphi)$ - actual contour

In case of setting the shaft in the claws function (7) takes a simplified form and consists only of compounds $\Delta R_{e}(\omega, \varphi)$ and $e(\omega, \varphi)$. In order to determine harmonic compounds which describe a measured roundness contour we apply well-known procedures that are in force in case of applying harmonic analysis to a shape contour description. A compound $e(\omega, \varphi)$ equals the value of the first harmonic compound describing the measured roundness contour. This, if taking the roundness contour description in a form of Fourier trigonometrical series, presents how much it is moved eccentrically with respect to the realized measuring base, in this case it is the axis determined by setting claws. 


\section{CONCLUSION}

Presented procedures can be used during developing the results of geometrical deviations measurements of large-size main journals' system of marine engines' crankshafts realized with the use of the measuring system with so called flexible shaft support developed in the Maritime University of Szczecin (Nozdrzykowski, 2010). This support method ensures elimination of elastic deformations of the shaft under its self-weight. It makes this measuring system universal when used for measurements of shafts set both in claws and prisms. A range of simulation studies realized on the basis of the developed calculating programme confirmed the accuracy of performed transformations and introduced relations applicable during measurements' results compilation. Simulation studies have been verified with a positive result with the measurements performed on the actual object. During the studies we measured the deviation of shape and crankshaft's main journals' axis location. The studies were performed on the middle-speed engine's crankshaft of the main drive of the vessel Buckau Wolf R8DV 136 (Nozdrzykowski and Janecki, 2014).

\section{REFERENCES}

Adamczak, S. (1998). Odniesieniowe metody pomiaru zarysów okrągłości części maszyn. Monografie, Studia, Rozprawy. Politechnika Świętokrzyska, Kielce.

Azirjawi, A. and Basheer, SK. (2018). New design solution for crankshaft. Proceedings of the asme international mechanical engineering congress and exposition, 2017, vol 2.

Dai, S.P., Gao, L. and Gao, K. (2006). The applications of measurement system for crankshaft. 1st International Symposium on Digital Manufacture, vol. 1-3, pp. 833-836.

Humienny, Z. (2001). Specyfikacje geometrii wyrobów (GPS) - wykład dla uczelni technicznych. Warszawa: Oficyna Wydawnicza Politechniki Warszawskiej.

Jakubiec, W. and Malinowski, J. (2004). Metrologia wielkości geometrycznych. Warszawa: WNT.

Malinowski, J. (1998). Pomiary długości i kąta. Warszawa: Wydawnictwo Szkolne i Pedagogiczne.

Meaedows, J.D. (1995). Geometric Dimensioning and Tolerancing: Appplications and Techniques for Use in Design, Manufacturing, and Inspection. New York: Marcel Dekker, Inc.

Nozdrzykowski, K. (2010). The determination and analysis of the total measurement uncertainty of roundness deviation. Scientific journals of the Maritime University of Szczecin, vol. 21, pp. 72-76.

Nozdrzykowski, K. and Janecki, D. (2014). Comparative studies of reference measurements of cylindrical surface roundness profiles of large machine components. Metrology and Measurement System, vol. XXI, No. 1, pp. 67-76 .

Sun, J., Wang, J. and Gui, C. (2010). Whole crankshaft beam-element finite-element method for calculating crankshaft deformation and bearing load of an engine. Proceedings of the institution of mechanical engineers part j - Journal Of Engineering Tribology, vol. 224, p. 299-303.

Quan, W., Wei, J., Zhao, YW., Sun, L.H. and Bianl, X.Y. (2011). Development of an Automatic Optical Measurement System for Engine Crankshaft. 2011 International Conference on Computational Science and Applications, pp. 68-75

Walczyk, W., Milenin, A. and Pietrzyk, M. (2011). Computer Aided Design of New Forging Technology for Crank Shafts. Steel Research International, vol. 82, pp. 187-194.

Żebrowska-Łucyk, S. (1979). Wpływ rodzaju okręgu odniesienia na wyniki oceny odchyłki kołowości. Mechanik, Nr. 1, s. 207-210. 